\title{
Managerial defections, promotion criteria and firm growth
}

\author{
Mehmet $\mathrm{Bac}^{\mathrm{a}, *}$, Ismail Saglam ${ }^{\mathrm{a}, \mathrm{b}}$ \\ ${ }^{a}$ Department of Economics, Bilkent University, Bilkent, Ankara, Turkey 06533 \\ ${ }^{\mathrm{b}}$ Princeton University, Princeton, NJ 08540, USA
}

Received 29 July 1996; received in revised form 10 February 1997; accepted 31 December 1997

\begin{abstract}
Junior managers' learning decisions and career expectations, promotion criteria, and parent firms' growth strategies are interdependent. We study this interdependence in a two-stage game where a junior manager invests in unobservable industry-specific learning in response to the firm's growth strategy. In the absence of a credible promotion criterion the firm is unable to insure itself fully against defections, growth is low and ex-post regrettable managerial promotions may occur. Higher growth relaxes promotion decisions and erodes managers' learning incentives, whereas lower growth generates the opposite effect but increases the likelihood of defections. (C) 1999 Elsevier Science B.V. All rights reserved.
\end{abstract}

Keywords: Sunk growth; Bayesian equilibrium; Ability acquisition; Promotions

JEL classification: M12; L14

\section{Introduction}

Leaving managers often establish successful rival firms: Rudolf Dassler left Adidas AG and established Puma AG in 1948, Steve Jobs and Steve Wozniak left respectively Atari and Hewlett-Packard and established in 1977 Apple Computer. A necessary condition for such successful defections is learning, the process

\footnotetext{
*Corresponding author. Tel.: +90 312 2664000; fax: +90 3122664948.

E-mail address: bac@bilkent.edu.tr (M. Bac)

0167-7187/99/\$ - see front matter (C) 1999 Elsevier Science B.V. All rights reserved. PII: S0167-7187(98)00009-5
} 
whereby junior managers acquire industry-specific knowledge (e.g., cost efficiency, market research). As growth within the ranks of the managerial hierarchy generates a potential for future defections, it also constitutes the basis for a successful extension of the firm. The acquisition of Nabisco Foods by the tobacco giant RJ Reynolds Inc. in 1985, which CEO Paul Sticht attributed directly to poor management, is a successful expansion that can be rationalized in terms of surplus junior managers in the corporation. The growth of professional service firms in particular depends on developing human capital inputs (e.g., Nelson, 1988). These firms pursue an up-or-out rule according to which promotions lead to partnership whereas nonpromoted individuals leave to their outside options, including establishing a rival by taking with them some of their former clients. There is an extensive management literature which emphasizes the ties between firm growth and managers' career and learning decisions. The present paper explores this interdependence using game-theoretic tools. Our analysis provides an explanation for and sheds light on the factors determining promotion decisions, differential growth and defection strategies as those exemplified above.

Managerial skills are to a large extent industry-specific. The first reference to this fact in economics literature dates back to Marshall (1890) who attributed firm-size asymmetries to differences in managerial ability. ${ }^{1}$ Later, the differential efficiency hypothesis in Industrial Organization (e.g., Demsetz, 1973) is founded on a similar premise. With a few exceptions ${ }^{2}$ the economics literature has neglected the interaction between firm growth and internal production of managerial abilities, in particular the resulting impact on promotion decisions and managerial defections that may establish successful rivals. ${ }^{3}$ These issues gain a

\footnotetext{
${ }^{1}$ Empirical management studies on CEO appointments lend strong support to this view. Kotter (1982) describes the typical general manager as an "expert" in his business. Tuckel and Siegel (1983) found that 54 percent of CEOs worked for only one employer, and according to Shetty and Peery (1976) 89 percent of CEO appointments came from within the firm, whereas 95 percent came from within the firm or from within the same or a related industry. Their findings thus suggest 6 percent CEO defections to a firm rivalling the parent. This may seem excessive inbreeding if, in fact, top management skills were universal and easily transferable across industries.

${ }^{2}$ Notable exceptions are Carmichael (1983); Ricarti-i-Costa (1988); Siow (1994). Demougin and Siow (1994) Demougin and Siow (1996) come closest to the issues we address here, but do not consider the firm's growth decision. In their model, the firm bears the cost of training junior managers, and the intensity of training determines the probability of promotions (managers do nothing to improve their inside and outside options). Though insightful in other respects, their model does not capture the relationships we study in this paper.

${ }^{3}$ In the related literature we can cite Prescott and Visscher (1980) where the firm's learning about junior managers' abilities takes time, which introduces a tradeoff between speed and "expected quality" of growth. Penrose (1959) formalized learning within large corporations in terms of a managerial constraint which consists of the number of "superior managers". Papers that acknowledge the common feeling among executives that managerial capital is an effective constraint on firm growth include Lucas (1978), and Kihlstrom and Laffont (1979). MacDonald (1982) models the manager's task as an optimal assignment problem involving heterogeneous factors and shows that factor output is increasing in the manager's information on these factors.
} 
special relevance in self-owned organizations involving a system of professional apprenticeship to develop human resources, culminating with promotion to partnership or defection/dismissal. Typical examples are law firms (e.g., Gilson and Mnookin, 1989), accounting and consulting firms (e.g., Maister, 1993), architecture and engineering firms, investment banks and physician groups.

Why do defections that hurt parent firms occur, and how do they relate to firm growth, promotion criteria and managerial learning? In this paper we focus on the parent's imperfect information about junior managers' abilities at the late stages of apprenticeship. Defection may occur if the parent underestimates a junior manager's accumulated industry-specific managerial ability. ${ }^{4}$ The parent, however, can avoid underestimating abilities by credibly committing itself to a promotion criterion, linking with precision senior-level wages to junior-level performance. This works as follows. If performance signals are correlated with ability, junior managers who observe a precise and respected relation between performance and senior-level wages will, as expected by the parent, invest in developing abilities. Strong learning incentives will generate a long-run supply of skilled managers and the parent firm will accordingly adopt a high growth strategy. Thus, if the firm can present a credible promotion criterion, under rational expectations and in the absence of external uncertainty the probability of both defections and ex-post unqualified promotions can be reduced substantially, while growth and learning decisions are set optimally. Our analysis shows that the lack of a precise, credible promotion criterion can (i) explain seemingly paradoxical behavior such as dismissal or defection of nonpromoted but high-ability managers, and (ii) generate interdependence between junior managers' incentives to invest on industry-specific abilities and the parent's growth strategy. ${ }^{5}$ We derive a negative equilibrium relationship between firm growth and managerial learning, and an endogenous promotion rule linking performance signals to senior level wage offers. In our model the parent firm who lacks a credible promotion criterion faces a dilemma: To prevent future unwanted departures it may adopt a high growth strategy today and give a signal that space will be created at the apex, but the level of growth must be compatible with junior managers' incentives to acquire corresponding

\footnotetext{
${ }^{4}$ A straightforward explanation for defections is external uncertainty with respect to outside options. If ex-post the junior manager privately observes a very attractive opportunity outside the parent, he will defect. Yet another explanation can be furnished by introducing an element of "control" in managers' objectives. Then, defections will arise from a conflict over control between senior and junior managers (see for example Baumol, 1959 and Marris, 1963).

${ }^{5}$ Malos and Campion (1995) present a similar argument in the context of professional service firms. To quote their conjecture, “...where a firm hires associates for their future partnership potential, it would be expected to provide both (a) strong, positive representations about the time and chances for making partner and (b) high-quality developmental opportunities to encourage an associate to remain with the firm. In firms where these representations are credible and sustained by historical data, the possibility of partnership will provide a strong incentive to [...] develop professional skills needed for promotion." Our model confirms this conjecture and explores growth and learning implications of the lack of a credible promotion criterion.
} 
specific abilities. Firm growth thus has a component which we call "strategic" in that it is aimed at avoiding defections of highly skilled managers, as opposed to growth for the sole purpose of meeting future demand.

We formalize in Section 2 the link between firm growth and managers' learning and defection decisions in a two-stage, extensive form game. In the first stage the parent firm chooses a growth level, then the junior manager decides on his unobservable learning effort to acquire ability. In the second stage the parent observes a signal about junior manager's ability and makes an offer, to which the junior manager responds with a binary defect/stay choice. We solve this game for its perfect Bayesian equilibrium in Section 3 and Section 4 under the assumption that credible commitments to promotion criteria are impossible. Two opposing forces that affect the level of firm growth are balanced in this equilibrium. The possibilities of defection and unqualified promotion generate uncertainty and increase the cost of growth, while junior manager's learning increases the stock of managerial abilities and makes growth beneficial. Uncertainty costs of growth have two facets: since the parent observes an imperfect signal about the ability of its junior manager, underestimation of ability, hence a low offer may cause defection whereas overestimation of ability, hence a high offer may promote unqualified managers. High growth "softens" the parent and relaxes equilibrium promotion decisions, but erodes managers' learning incentives. In the resulting equilibrium the parent does not insure itself completely against defections and unqualified promotions, but keeps an optimal balance between managers' learning incentives and growth. In Section 5 we show that the parent can avoid defections and grow optimally if it can commit itself to a promotion criterion. We discuss our results and provide some extensions in Section 6.

\section{The model}

We consider a simple hierarchical organization, a monopoly owned by its senior manager S, where lower levels of the hierarchy are represented by a junior manager $J$. The extension to more than one junior manager is not difficult and we briefly discuss this case in Section 6. We use an extensive form game to study the interaction between $J$ and $S$, as shown in Fig. 1 . In the first (entry) stage $S$ chooses the level of growth, $q$. We define growth as a sunk expenditure whose return, to be realized in the second stage, is positively related to the stock of managerial ability. Growth should thus be understood in a broad sense, including establishing a new plant, an acquisition or overseas investment. ${ }^{6} \mathrm{~J}$ 's industry-specific ability is zero

\footnotetext{
${ }^{6}$ The variable $q$ can also be interpreted as a sunk training cost, by $\mathrm{S}$ on J's ability, supplementing J's own learning effort introduced below. This interpretation may affect our results only if S's training expenditures affect J's cost of learning effort in a particular way. We briefly discuss this issue in Section 6.
} 


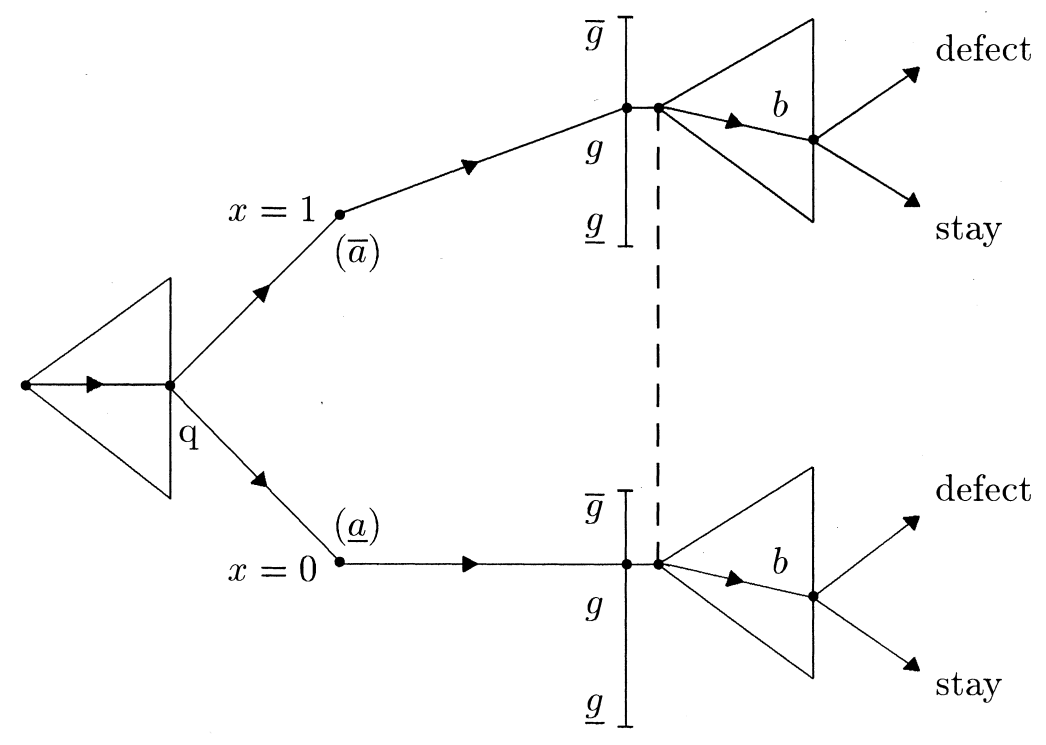

\section{Growth Learning Signal Offer Defection \\ Decision}

Fig. 1. Extensive form of the game.

during the entry stage. He receives a competitive wage normalized to zero, observes $q$ and chooses a learning effort $\alpha$ which can take on two values, $\underline{\alpha}$ (low) or $\bar{\alpha}$ (high). We allow $\mathrm{J}$ to use a mixed effort strategy, denoted $x=\operatorname{prob}(\alpha=\bar{\alpha})$. The cost of learning effort is denoted $d(\alpha)$, with $d(\bar{\alpha})>d(\underline{\alpha})$. We call "ability" the managerial capital resulting from effort devoted to learning activities. We assume a simple learning technology according to which (or, choose units so that) learning effort and ability are identical, both unobservable to S. S's ability is common knowledge and remains constant.

The second stage of the game (called the defection stage) is thus played under asymmetric information where $\mathrm{J}$ is the informed player. $\mathrm{S}$ formulates beliefs about the ability of $\mathbf{J}$ on the basis of her expectations about $\mathbf{J}$ 's past incentives to acquire a high ability and a signal $g$, which is an imperfect indicator of ability (such as J's entry-stage performance). Each effort (ability) level generates a distribution function for the signal $g$. We assume that

(A1) $g$ has support $[g, \bar{g}]$ with cumulative distribution function $F_{\alpha}(g)$ and continuous density function $f_{\alpha}(g)$ strictly positive. Moreover, (Monotone likelihood ratio) 


$$
\frac{f_{\bar{\alpha}}(g)}{F_{\bar{\alpha}}(g)}>\frac{f_{\underline{\alpha}}(g)}{F_{\underline{\alpha}}(g)}, g \in(\underline{g}, \bar{g}] .
$$

That is, ability $\alpha$ induces a particular distribution $F_{\alpha}(g)$ over $[g, \bar{g}]$, and the monotone likelihood ratio assumption implies that a high value for the signal $g$ is relatively more likely to result from J who acquires high ability $\bar{\alpha}$. In this section and the next two, we assume that $g$ is not contractible, that is, at the outset $\mathrm{S}$ cannot credibly commit herself to a signal-wage offer scheme for the defection stage. The implication of this incomplete contracting assumption is clarified in Section 5. Williamson (1985) provides a thorough discussion of the difficulties involved in finding a satisfactory and objective signal or criterion to provide high-powered incentives in organizations.

Having observed a noisy signal $g$ about J's ability and updated her beliefs, S makes a wage offer denoted $b$. If $\mathrm{J}$ accepts, he stays with $\mathrm{S}$ and the game ends. The alternative option of $\mathbf{J}$ is to defect and establish a rival. In this case the parties obtain their duopoly profits. ${ }^{7}$ We choose to keep our principal-agent assumption at the defection stage and attribute the whole bargaining power to $\mathrm{S}$ for simplicity. With wage bargaining at the defection stage and a more symmetric distribution of the bargaining power, defection is less likely than under our principal-agent assumption (because the surplus that $\mathbf{J}$ obtains over his outside option may, for some realizations of the performance signal $g$, be sufficient to deter defection). But defection still occurs with positive probability provided that the surplus that $\mathbf{J}$ obtains thanks to his bargaining power is not too large, for the same reasons as it occurs under the principal-agent assumption. Indeed, one necessary condition for unwanted defections is the firms' inability or unwillingness to credibly provide their junior managers a sufficiently large ex-post surplus and bargaining power. Another condition, which we discuss in Section 5, is the inability to present a credible promotion criterion.

The defection-stage monopoly profit of $\mathrm{S}$ is represented by the function $\Pi(q, \alpha)$ where $q$ denotes the capacity extension generated by growth, and $\alpha$, the ability of

\footnotetext{
${ }^{7}$ In the context of an oligopolistic industry structure, J's defection may also be thought of as leaving to a rival firm's management team. The analysis below would be unchanged, replacing J's duopoly profit by his best outside option. However, the oligopolistic industry structure presents additional interesting questions because firms can hire each other's managers and managers may establish rival firms, which complicates the firms' growth and the managers' learning decisions. We take up this issue briefly in Section 6.

${ }^{8}$ To see this, consider the extreme case where $\mathrm{J}$ has the whole bargaining power at the defection stage, thus captures the whole surplus from continuation. This is a trivial case where the junior manager team $(\mathrm{J})$ has the complete power to overtake the control of the parent firm from senior managers $(\mathrm{S})$. Then obviously defections will not occur. Introducing two-sided imperfect information about J's ability in the defection stage does not promise additional insights about the questions we pose in this paper. If $\mathrm{J}$ also ignores his true ability at the defection stage, the only new feature of the resulting equilibrium outcome will be miscalculated defections, as $\mathrm{J}$ may overestimate his ability and defect.
} 
$\mathrm{J}$, captures total abilities of the managers participating in top-level decisions. We assume the following:

(A2) $\Pi(q, \alpha)$ is continuous, strictly concave in $q$, and increasing in $\alpha$. $\Pi(q, \alpha)$ admits a global maximum in $q$, and for $\alpha_{1}>\alpha_{2}$ we have $\operatorname{argmax}_{q} \Pi\left(q, \alpha_{1}\right)>$ $\operatorname{argmax}_{q} \Pi\left(q, \alpha_{2}\right)$.

According to (A2) a firm operated by highly skilled managers makes a larger profit and the optimal size of the firm increases with its stock of managerial ability. We assume that managerial ability is acquired at the junior level and remains constant thereafter. Let $\bar{V}$ denote J's expected payoff at the defection stage. His total expected payoff as viewed from the entry stage is then

$$
V^{0}=-x d(\bar{\alpha})-(1-x) d(\underline{\alpha})+\bar{V} .
$$

The firm has an initial output capacity which we take as the profit maximizing level of output at the existent stock of managerial ability. Letting $\Pi_{E}$ denote the maximum first-stage profit of $\mathrm{S}$, we write the objective of $\mathrm{S}$ as

$$
\max _{q} \Pi^{0}=\max _{q}\left\{\Pi_{E}-k(q)+\bar{\Pi}\right\} .
$$

In (2), $k(q)$ is a strictly convex function representing the physical cost of growth and $\bar{\Pi}$ denotes S's expected profits at the defection stage. The expressions of $\bar{\Pi}$ and $\bar{V}$ are derived in Section 3 and Section 4, Eqs. (7) and (8), respectively. Without loss of generality we drop $\Pi_{E}$ from the expression of $\Pi^{0}$ hereafter, and assume a stationary market demand throughout the analysis to set aside the issue of nonstrategic growth.

We adopt perfect Bayesian equilibrium (PBE) as the solution concept for this game, which requires strategies be sequentially rational and beliefs be obtained through Bayes' rule whenever possible. Thus the following conditions must obtain in the reversed order of events: (E1) J's decision at the defection stage is optimal given his ability and the offer he receives from S; (E2) S makes an optimal offer, given (E1) and her posterior beliefs $\mu(\bar{\alpha} \mid g)$ about J's ability which she computes through Bayes' rule; (E3) J's (possibly mixed) effort strategy $x=$ prob $(\alpha=\bar{\alpha})$ in the entry stage is optimal given the growth level $q$ and subsequent strategies; and (E4) $\mathrm{S}$ chooses an optimal growth level given all subsequent strategies.

The entry-stage strategies $x$ and $q$ affect the strategies and payoffs in the defection stage directly as shown in (1) and (2), and indirectly through the posterior beliefs of $\mathrm{S}^{9}$.

\footnotetext{
${ }^{9}$ A general weakness of the PBE concept which our game avoids is that the specification of beliefs off the equilibrium path (where Bayes' rule cannot be applied) is left to the modeler. The present game avoids this problem because all signals $g \in[g, \bar{g}]$ are received with positive probability, hence Bayes' rule can be applied for all realizations of $g$. In what follows we refer to PBE as "equilibrium".
} 


\section{The defection stage}

In this section we specify the parties' defection stage payoffs as a function of entry-stage strategies and describe S's process of updating beliefs as a function of J's strategy, growth, and the performance signal $g$. Consider first J's defection to establish a rival firm. The resulting duopoly profits are denoted $\left\{\Pi_{\mathrm{J}}^{\mathrm{D}}(\alpha), \Pi_{\mathrm{S}}^{\mathrm{D}}(\alpha)\right\}$ where $\alpha$ stands for J's ability (the output choices corresponding to ability $\alpha$ are suppressed for simplicity). We take J's postdefection duopoly profit $\Pi_{\mathrm{J}}^{\mathrm{D}}(\alpha)$ as net of capacity instalment costs. ${ }^{10}$ To characterize the outcome $\left\{\Pi_{\mathrm{J}}^{\mathrm{D}}(\alpha), \Pi_{\mathrm{S}}^{\mathrm{D}}(\alpha)\right\}$, one has to make further assumptions about the duopoly game (demand and cost structures, etc.) but this is not essential for our purpose. We assume that

$$
\Pi_{\mathrm{J}}^{\mathrm{D}}(\bar{\alpha})>\Pi_{\mathrm{J}}^{\mathrm{D}}(\underline{\alpha}) \geqslant 0 \text { and } \Pi_{\mathrm{S}}^{\mathrm{D}}(\underline{\alpha})>\Pi_{\mathrm{S}}^{\mathrm{D}}(\bar{\alpha}) \geqslant 0 .
$$

(A3) states that J's (S's) duopoly profit is positively (negatively) related to J's ability. Most duopoly models coupled with (A2) will actually predict (A3). Let us introduce the notation $\bar{b}=\Pi_{\mathrm{J}}^{\mathrm{D}}(\bar{\alpha})$ and $\underline{b}=\Pi_{\mathrm{J}}^{\mathrm{D}}(\underline{\alpha})$, and let $\bar{q}$ maximize

$$
-k(q)+\Pi(q, \bar{\alpha})-\bar{b} .
$$

We assume that S's monopoly profit given J's ability is larger than the sum of duopoly profits: $\Pi(q, \alpha)>\Pi_{\mathrm{S}}^{\mathrm{D}}(\alpha)+\Pi_{\mathrm{J}}^{\mathrm{D}}(\alpha)$ where $\alpha=\bar{\alpha}, \underline{\alpha}$ (note that $q$ is sunk at the defection stage). Furthermore,

$$
d(\bar{\alpha})-d(\underline{\alpha})<\bar{b}-\underline{b}<\Pi(q, \bar{\alpha})-\Pi(q, \underline{\alpha}) \text { for all } q,
$$

so that $\mathrm{J}$ prefers $\bar{\alpha}$ to $\underline{\alpha}$, and $\mathrm{S}$ prefers retaining the type- $\bar{\alpha}$ of $\mathrm{J}$ by matching the wage differential $\bar{b}-\underline{b} .{ }^{\frac{1}{11}}$ As a reference, we characterize the solution of the game under observable ability (the second stage is a perfect information game). The following result follows from our assumptions.

Proposition 1. If $\alpha$ is observable, in equilibrium $J$ will choose $x=1(\alpha=\bar{\alpha}), S$ will offer $\bar{b}$ at the defection stage and $J$ will stay. This outcome is efficient.

\footnotetext{
${ }^{10}$ The duopoly profits are both independent of growth $q$. S's profit $\Pi_{\mathrm{S}}^{\mathrm{D}}(\alpha)$ does not depend on $q$ because any growth is excessive and $\mathrm{S}$ definitely operates below capacity $q$ if $J$ defects. The direct potential impact of $q$ on $\Pi_{\mathrm{J}}^{\mathrm{D}}(\alpha)$ is assumed away to simplify the analysis. We briefly discuss the possibility that growth may be used as a defection deterrence device in Section 6 .

${ }^{11}$ Because $\alpha$ is not observable, if the first inequality in (A4) does not hold, the overall game has a unique "bad" equilibrium where J always chooses the low ability, S adopts a corresponding low growth, and defection is never observed. If the first inequality in (A4) does not hold but $d(\bar{\alpha})-d(\underline{\alpha})<$ $\Pi(q, \bar{\alpha})-\Pi(q, \underline{\alpha})$ and ability is observable and contractible, there is an equilibrium where $\mathrm{S}$ offers ability-contingent wages and $\mathbf{J}$ stays. If the first inequality holds but the second is reversed, $\mathrm{J}$ always acquires the high ability and defects with probability one. We confine the analysis below to the interesting case where (A4) holds.
} 
The strategies $x=1$ and $q=\bar{q}$ form the unique entry-stage equilibrium of the perfect information game. Given (A4) and thanks to observability of $\alpha$, learning incentives are restored and the level of growth maximizes the joint surplus. For the case in which the first inequality in (A4) is reversed, $J$ acquires the low ability with probability one $(x=0)$ and we let $q$ denote the corresponding optimal growth level.

We now turn back to the case of unobservable ability. The entry-stage strategies affect the defection-stage of the game as follows. J's learning strategy on the one hand determines the distribution of the performance signal $g$, hence affects S's information set when she updates beliefs to make a wage offer to J. The wage offer compared with the outside option determines whether $\mathbf{J}$ stays or defects. On the other hand, duopoly profits in the event of defection and monopoly profits of $\mathrm{S}$ if $\mathbf{J}$ stays are both functions of J's learning strategy. Growth has two cost elements in this model. The cost of sunk growth expenditures are represented by the function $k(q)$. The second cost element, as we show in Section 4, owes to uncertainty about whether growth will be matched by an appropriate increase in the internal supply of managerial abilities. Since the firm neither has total control over nor directly observes J's ability, the latter may well turn out to be incompatible with the executive position generated by growth. As a result, the firm may adopt a "prudent" growth strategy if it is pessimistic about J's learning incentives and potential ability.

We describe below S's process of updating beliefs and derive the optimal wage offer as a function of updated beliefs. Fix a path of entry-stage strategies and let $g$ be observed. $\mathrm{S}$ will make a wage offer at the defection stage on the basis of her posterior belief that she faces a high-ability $\mathrm{J}$, which can be computed through Bayes' rule as

$$
\mu(\bar{\alpha} \mid g)=\frac{x F_{\bar{\alpha}}(g)}{x F_{\bar{\alpha}}(g)+(1-x) F_{\underline{\alpha}}(g)} .
$$

Three remarks about $\mu(\bar{\alpha} \mid g)$ are in order: First, (A1) implies that $\mu(\bar{\alpha} \mid g)$ is increasing in $g$ given $x \in(0,1)$, i.e., if a better performance signal is observed $\mathrm{S}$ infers that $\mathrm{J}$ is more likely to have ability $\bar{\alpha}$, given J's learning strategy $x$. Second, $\mu(\bar{\alpha} \mid g) \leqslant x$ for all $g \in[g, \bar{g}]$. And third, by the interpretation of equilibrium as the predicted path of strategies, $\mathrm{S}$ will be able to compute $\mu$ along the equilibrium path despite the fact that neither $x$ nor $\alpha$ are observable.

We can now determine S's optimal wage offer $b^{*}$ as a function of her posterior belief given in (4). Because monopoly profits exceed total duopoly profits, when J's ability is common knowledge S's optimal offer is the minimum wage that prevents J's defection. Suppose now that $\mu \in(0,1)$. Since any offer accepted by type- $\bar{\alpha}$ is also accepted by type- $\underline{\alpha}$ of $\mathrm{J}, \mathrm{S}$ has two choices: to make a screening offer accepted only by type- $\underline{\alpha}$ or a nonscreening offer accepted by both types. The optimal screening offer is $\underline{b}$ and the optimal nonscreening offer is $\bar{b}$. Since $\mathrm{J}$ will stay if $\mathrm{S}$ makes a nonscreening offer, the corresponding net expected profit of $\mathrm{S}$ is 
$\mu \Pi(q, \bar{\alpha})+(1-\mu) \Pi(q, \underline{\alpha})-\bar{b}$. If $\mathrm{S}$ makes the screening offer $\underline{b}$, J will stay with probability $(1-\mu)$ and defect with probability $\mu$, which yields $\mathrm{S}$ the net expected profit $\mu \Pi_{\mathrm{S}}^{\mathrm{D}}(\bar{\alpha})+(1-\mu) \Pi(q, \underline{\alpha})-\underline{b}$. It follows that $\mathrm{S}$ will offer the higher nonscreening wage if $\mu \Pi(q, \bar{\alpha})-\bar{b} \geqslant \mu \Pi_{\mathrm{S}}^{\mathrm{D}}(\bar{\alpha})-\underline{b}$, or if

$$
\mu(\bar{\alpha} \mid g) \geqslant \frac{\bar{b}-\underline{b}}{\Pi(q, \bar{\alpha})-\Pi_{\mathrm{S}}^{\mathrm{D}}(\bar{\alpha})} \equiv M(q),
$$

and the lower screening wage otherwise. This condition plays an important role in the analysis presented in Section 4. $M(q)$, the ratio defined by the middle term in (5), never exceeds one. This follows from (A4) and the fact that $\Pi(q, \bar{\alpha})>$ $\Pi_{\mathrm{J}}^{\mathrm{D}}(\bar{\alpha})+\Pi_{\mathrm{S}}^{\mathrm{D}}(\bar{\alpha})$ for all $q$. The cost of paying the wage differential $\bar{b}-\underline{b}$ is always lower than the benefit from retaining a junior manager of type $\bar{\alpha}$. The lower is $M(q)$, the higher is S's valuation of a type- $\bar{\alpha}$ manager, which implies that S may offer the high nonscreening wage for a wider range of performance signals. Stated differently, $\mathrm{S}$ is willing to take a higher risk in order to avoid defection if $M(q)$ is low. Note also that $\partial M(q) / \partial q<0$ for $q \leqslant \bar{q}$. This is quite intuitive: a higher growth increases the benefit of retaining the high-ability manager, hence the cost-benefit ratio $M(q)$ declines as $q$ approaches $\bar{q}$.

\section{Equilibrium growth and managerial ability}

The condition in (5) provides the link between defection-stage strategies, the performance signal and entry-stage strategies. We explore this link below. Given $x$ and $q$, the signal $g_{\mathrm{C}}$ which satisfies (5) with equality (assuming for the moment that such a $g$ exists) is a critical level of $g$ such that the corresponding beliefs make $\mathrm{S}$ indifferent between the screening offer $\underline{b}$ and the nonscreening offer $\bar{b}$. Since $g_{\mathrm{C}}$ depends on $x$ and $q$, we can define a locus $g_{\mathrm{C}}(x, q)$ which partitions $[g, \bar{g}]$ into two intervals such that $b^{*}=\bar{b}$ if $g \in\left[g_{\mathrm{C}}(x, q), \bar{g}\right]$ and $b^{*}=\underline{b}$ otherwise. These two intervals have straightforward interpretations: the upper signal interval corresponds to "good performance signals" that lead $\mathrm{S}$ to make the nonscreening offer $\bar{b}$. S is pessimistic about J's ability in the lower signal interval and makes the screening offer $\underline{b}$. The main objective of the following analysis is to clarify the dependence of the critical performance signal on firm growth and J's learning strategy. To be more precise, define the set $\Omega=\{g \mid g$ satisfies (5) given $x, q$.$\} . Then$

$$
g_{\mathrm{C}}(x, q)=\left\{\begin{array}{cl}
\inf \Omega & \text { if } \Omega \neq \varnothing \\
\bar{g} & \text { if } \Omega=\varnothing
\end{array}\right.
$$

That is, if $\mu(\bar{\alpha} \mid g)<M(q)$ for all $g$, we let $g_{\mathrm{C}}(x, q)=\bar{g}$, which means that S will offer $\underline{b}$ no matter the value of $g$. This is an extreme case in that $\mathrm{S}$ always screens $\mathrm{J}$. On the other hand if $\mu(\bar{\alpha} \mid g) \geqslant M(q)$ for some $g$, then we set $g_{\mathrm{C}}(x, q)$ equal to the 
smallest such $g$. The following lemma explores the dependence of $g_{\mathrm{C}}(x, q)$ on $x$ and $q$.

Lemma 1. (i) $g_{\mathrm{C}}(x, q)=\bar{g}$ if $x \in[0, M(q)]$, and $g_{\mathrm{C}}(x, q)=g$ if $x \in[Z(q), 1]$ where, given a growth level $q, Z(q)>M(q)$ is a critical mixed learning strategy of $J$ such that $S$ always makes the high nonscreening wage offer for $x \geqslant Z(q)$. (ii) For $x \in(M(q), Z(q))$ and $q \in[0, \bar{q}], g_{\mathrm{C}}(x, q)$ is nonincreasing in $x$ and $q$.

Proof. See Appendix A.

Part (i) of Lemma 1 concerns the extreme cases where S's wage offer does not depend on the performance signal $g$. J will be offered $\bar{b}(\underline{b})$ with probability one if his learning incentives are sufficiently strong (weak). For the intermediate range of learning incentives, Part (ii) of Lemma 1 stipulates that $\mathbf{J}$ is more likely to be offered the high wage $\bar{b}$ if, as anticipated by $\mathrm{S}$, he puts more weight on acquiring the high ability. The lemma also shows that a higher growth makes $\mathrm{S}$ more vulnerable to defection, as $\mathrm{S}$ is more likely to offer $\bar{b}$ if a higher growth is adopted, given J's learning strategy $x$. This manifests itself in a lower cost-benefit ratio $M(q)$ and a widening of the upper signal interval $\left[g_{\mathrm{C}}(x, q), \bar{g}\right]$ where $\mathrm{S}$ is optimistic about J's ability and makes the nonscreening offer. In that sense, a high growth strategy increases the firm's valuation of industry-specific managerial abilities ex-post and "softens" its promotion decision.

The dependence of $g_{\mathrm{C}}(x, q)$ on $x$ is visualized in Fig. 2 for different levels of growth. Given $q$, the right hand side of (5) is fixed at $M(q)$. As mentioned, $g_{\mathrm{C}}(x, q)=\underline{g}$ for all $x \in[Z(q), 1], \mathrm{S}$ will always offer $\bar{b}$ and $\mathrm{J}$ will stay. As we decrease $x$ in the interval $(M(q), Z(q))$, Lemma 1(ii) applies and $g_{\mathrm{C}}(x, q)$ increases. For lower values of $x, \mathrm{~S}$ is less willing to offer $\bar{b}$ when she observes low values of $g$, and for $x \leqslant M(q) \mathrm{S}$ will never offer $\bar{b}$, which corresponds to $g_{\mathrm{C}}(x, q)=\bar{g}$. On the other hand, an increase in $q$ will shift $g_{\mathrm{C}}(x, q)$ to the left. The interval $\left[g_{\mathrm{C}}(x, q), \bar{g}\right]$ has a nice interpretation: it is a promotion criterion generated by a given pair of growth and learning strategies, linking observations of a signal about J's ability to S's wage offer at the defection stage. We determine the equilibrium promotion criterion endogenously in the sequel.

We proceed with the analysis of entry-stage strategies. To obtain the expression of J's expected payoff as viewed from the outset, note that if $\mathrm{J}$ acquires the high ability $\bar{\alpha}$, he guarantees the payoff $\bar{b}$ at the defection stage. If $\mathrm{J}$ acquires the low ability $\underline{\alpha}$, his payoff will depend on the signal $g$; he will accept S's wage offers, $\underline{b}$ with probability $F_{\underline{\alpha}}\left(g_{\mathrm{C}}\right)$ and $\bar{b}$ with probability $1-F_{\underline{\alpha}}\left(g_{\mathrm{C}}\right)$. Combining these terms yields the expression in (7).

$$
V^{0}=-x d(\bar{\alpha})-(1-x) d(\underline{\alpha})+x \bar{b}+(1-x)\left[F_{\underline{\alpha}}\left(g_{\mathrm{C}}\right) \underline{b}+\left(1-F_{\underline{\alpha}}\left(g_{\mathrm{C}}\right)\right) \bar{b}\right] .
$$

Let $x^{*}(q)$ maximize $V^{0}$, hence be J's best reply to $q$. Since $x^{*}(q)$ may depend on $q$ 


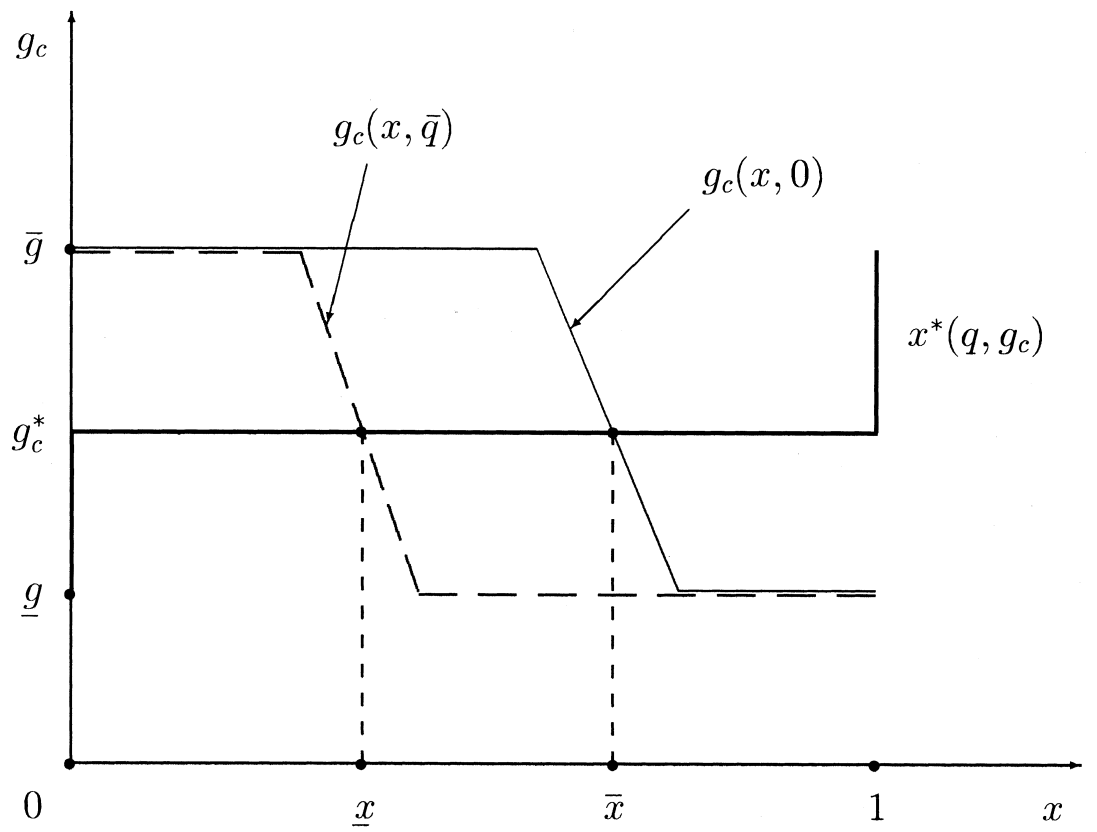

Fig. 2. The critical performance signal and J's learning decision.

only via $g_{C}$, we investigate J's behavior first by changing $g_{\mathrm{C}}$ parametrically. We have $F_{\underline{\alpha}}\left(g_{\mathrm{C}}\right)=0$ for $g_{\mathrm{C}}=\underline{g}$ and (7) becomes $V^{0}=-x d(\bar{\alpha})-(1-x) d(\underline{\alpha})+\bar{b}$. Then the best strategy for $\mathrm{J}$ is clearly $x^{*}=0$. On the other hand, if $g_{\mathrm{C}}=\bar{g}$, we have $F_{\underline{\alpha}}(\bar{g})=1$ and $\mathrm{S}$ offers $\underline{b}$ no matter $g$. In this case (A4) implies that the best strategy for $\mathrm{J}$ is $x^{*}=1$ and to defect later. Below we show that equilibria in pure learning strategies do not exist, but construct one in mixed strategies.

The locus $x^{*}\left(g_{\mathrm{C}}\right)$ in Fig. 2 describes J's learning decision as a function of $g_{\mathrm{C}}$. A low value of $g_{\mathrm{C}}$ means a lax promotion criterion, that is, a higher probability of being offered the high nonscreening wage $\bar{b}$. If this probability is sufficiently high, J chooses $\underline{\alpha}\left(x^{*}=0\right)$. If the promotion criterion is tight $\left(g_{\mathrm{C}}\right.$ is high and the expected value of $\mathrm{J}$ 's inside option is low) then $\mathrm{J}$ will acquire ability $\bar{\alpha}$ and guarantee a high outside option value $\bar{b}$. There is a single value $g_{\mathrm{C}}^{*}$ of the signal $g$ for which J's learning strategy is mixed $x \in(0,1)$, that is, for which we have $F_{\underline{\alpha}}\left(g_{\mathrm{C}}^{*}\right)(\bar{b}-\underline{b})=d(\bar{\alpha})-d(\underline{\alpha})$ from (7). This indifference condition balances the expected benefit and cost of exerting effort to acquire ability $\bar{\alpha}$. Thus, as shown in Fig. 2, only a portion of the locus $x^{*}\left(g_{\mathrm{C}}^{*}\right)$ represents $x^{*}(q)$, J's best reply consistent with S's growth strategy, her posterior beliefs and wage offer at the defection stage. The relevant portion of $x^{*}\left(g_{\mathrm{C}}^{*}\right)$ is identified on the horizontal axis by the interval $\left(\underline{x}=x^{*}(\bar{q}), \bar{x}=x^{*}(0)\right)$. In Proposition 3 we show that equilibrium growth cannot exceed $\bar{q}$; Lemma 2 describes J's best reply $x^{*}(q)$ to $q \in[0, \bar{q}]$ : 
Lemma 2. Equilibrium learning strategy of $J$ lies in the interval $(\underline{x}, \bar{x})$ where $0<\underline{x}<\bar{x}<1, \underline{x}=x^{*}(\bar{q})$ and $\bar{x}=x^{*}(0)$. Moreover, $x^{*}(q)$ is decreasing in $q$.

Proof. See Appendix A.

Thus, a higher growth relaxes the firm's promotion decision, thereby reduces J's benefit from investing on high ability. In Section 5 we show that the strategic interaction between growth and learning disappears if at the beginning of their relationship $S$ is able to present $\mathbf{J}$ a credible promotion criterion. In the absence of such a criterion, the promotion interval $\left[g_{\mathrm{C}}^{*}, \bar{g}\right]$ where $\mathrm{J}$ is offered $\bar{b}$ will be determined by (noncooperative) entry-stage strategies. The lower bound $g_{\mathrm{C}}^{*}$ of the "promotion range" is determined through J's indifference condition

$$
F_{\underline{\alpha}}\left(g_{\mathrm{C}}^{*}\right)=\frac{d(\bar{\alpha})-d(\underline{\alpha})}{\bar{b}-\underline{b}},
$$

where the right hand side is J's cost/benefit ratio for acquiring a high ability. Note that $F_{\alpha}\left(g_{\mathrm{C}}^{*}\right)<1$ by (A4), hence $g_{\mathrm{C}}^{*}<\bar{g}$. The following proposition links the endogenous promotion criterion to the individual costs and benefits of acquiring managerial ability:

Proposition 2. Increases in $[d(\bar{\alpha})-d(\underline{\alpha})] /[\bar{b}-\underline{b}]$, J's cost/benefit ratio associated with acquiring a high ability, will tighten the equilibrium promotion criterion (increase $g_{\mathrm{C}}^{*}$ ).

$\mathrm{S}$ will screen $\mathbf{J}$ in a wider range of performance signals if (i) acquiring a high ability is more costly and/or (ii) the differential ability has a smaller impact on J's defection option, which means that managerial ability is less industry-specific. Both factors tend to reduce J's incentives to acquire a high ability, thereby tighten the equilibrium promotion criterion. In the limit, as J's net benefit from acquiring a high ability vanishes, $\mathrm{S}$ will always offer the low screening wage $\underline{b}$. This corresponds to $g_{\mathrm{C}}^{*}=\bar{g}$.

The final step of the analysis is to characterize S's equilibrium growth strategy. Recall that for $g \geqslant g_{\mathrm{C}}^{*} \mathrm{~S}$ will offer $\bar{b}$ and $\mathrm{J}$ will accept. S's expected payoff is then

$$
x^{*}(q)\left(1-F_{\bar{\alpha}}\left(g_{\mathrm{C}}^{*}\right)\right)[\Pi(q, \bar{\alpha})-\bar{b}]+\left(1-x^{*}(q)\right)\left(1-F_{\underline{\alpha}}\left(g_{\mathrm{C}}^{*}\right)\right)[\Pi(q, \underline{\alpha})-\bar{b}] .
$$

On the other hand, for $g<g_{\mathrm{C}}^{*} \mathrm{~S}$ offers $\underline{b}$ which $\mathrm{J}$ will accept if his ability is $\underline{\alpha}$ and reject if his ability is $\bar{\alpha}$. This yields $\mathrm{S}$ the expected payoff

$$
\left(1-x^{*}(q)\right) F_{\underline{\alpha}}\left(g_{\mathrm{C}}^{*}\right)[\Pi(q, \underline{\alpha})-\underline{b}]+x^{*}(q) F_{\bar{\alpha}}\left(g_{\mathrm{C}}^{*}\right) \Pi_{\mathrm{S}}^{\mathrm{D}}(\bar{\alpha}) .
$$

Combining these terms we obtain the expression in (8): 


$$
\begin{aligned}
\max _{q} \Pi^{0}= & \max _{q}\{-k(q) \\
& +x^{*}(q)\left[\left(1-F_{\bar{\alpha}}\left(g_{\mathrm{C}}^{*}\right)\right)[\Pi(q, \bar{\alpha})-\bar{b}]+F_{\bar{\alpha}}\left(g_{\mathrm{C}}^{*}\right) \Pi_{\mathrm{S}}^{\mathrm{D}}(\bar{\alpha})\right] \\
& \left.+\left(1-x^{*}(q)\right)\left[\Pi(q, \underline{\alpha})-\bar{b}+(\bar{b}-\underline{b}) F_{\underline{\alpha}}\left(g_{\mathrm{C}}^{*}\right)\right]\right\} .
\end{aligned}
$$

We let $q^{*}$ denote the solution to (8). The strategy pair $\left\{x^{*}, q^{*}\right\}$ must satisfy equilibrium properties E3 and E4: given $x^{*}(q), q^{*}$ must solve (8) and, $x^{*}\left(q^{*}\right)$ must maximize (7) given $q^{*}$. In this equilibrium situation the firm's conjecture about its junior manager's best learning reply to the growth level will actually be fulfilled, and growth will be (ex-ante) consistent with the junior manager's learning incentive. Proposition 3 below characterizes entry-stage equilibrium strategies.

Proposition 3. Equilibrium growth is less than first-best $\left(q^{*}<\bar{q}\right)$, J's learning strategy is completely mixed $x^{*} \in(M(\bar{q}), Z(\bar{q})$ ), and defection (of a high-ability $J$ ) occurs with strictly positive probability $x^{*} F_{\bar{a}}\left(g_{\mathrm{C}}^{*}\right)$.

Proof. See Appendix A.

The result that growth is lower in the unobservable than in the observable ability case should be expected. Unobservability of J's ability and the fact that $g$ is an imperfect indicator of ability reduce the expected benefit of growth. Equilibrium growth is suboptimal because $\mathrm{S}$ faces two types of risk when she decides on growth: retaining the low-ability $\mathrm{J}$ (where the corresponding optimal growth is $q$ ) and losing the high-ability $\mathbf{J}$ (where any positive growth is excessive). The question we address in Proposition 4 is whether growth will exceed the optimal level corresponding to retaining a low-ability $\mathrm{J}$ with probability one, i.e., whether $q^{*}>\underline{q}$. We refer to this case as the optimistic growth equilibrium. Let us define

$$
Y=\frac{\left[F_{\underline{\alpha}}\left(g_{\mathrm{C}}^{*}\right) / F_{\bar{\alpha}}\left(g_{\mathrm{C}}^{*}\right)-1\right](\bar{b}-\underline{b})-\Pi_{\mathrm{S}}^{\mathrm{D}}(\bar{\alpha})+\Pi(\underline{q}, \underline{\alpha})-\underline{b} F_{\bar{\alpha}}\left(g_{\mathrm{C}}^{*}\right)}{\left[F_{\underline{\alpha}}\left(g_{\mathrm{C}}^{*}\right) / F_{\bar{\alpha}}\left(g_{\mathrm{C}}^{*}\right)-1\right](\bar{b}-\underline{b})-\Pi_{\mathrm{S}}^{\mathrm{D}}(\bar{\alpha})+\Pi(\underline{q}, \bar{\alpha})},
$$

which we derive in the proof of Proposition 4. Note that $Y<1$. Optimistic growth requires a sufficiently large differential marginal benefit for abilities $\bar{\alpha}$ and $\underline{\alpha}$, evaluated at $q=q$. The number $Y$ determines how large this differential marginal benefit of growth should be.

Proposition 4. In equilibrium, the firm will adopt an optimistic growth strategy if $\partial \Pi(q, \underline{\alpha}) / \partial q<Y \partial \Pi(q, \bar{\alpha}) / \partial q$, that is, if the marginal benefit of growth at $q=\underline{q}$ with a high-ability $J \overline{i s}$ sufficiently higher than with a low-ability $J$. The case for optimistic growth gets stronger if $\Pi_{\mathrm{S}}^{\mathrm{D}}(\bar{\alpha})$ and $\Pi(\underline{q}, \underline{\alpha})$ increase and/or $\Pi(\underline{q}, \bar{\alpha})$ becomes small. 
Proof. See Appendix A.

$\partial \Pi(q, \underline{\alpha}) / \partial q<\partial \Pi(q, \bar{\alpha}) / \partial q$ is already implied by (A2). More is required for optimistic growth: $(1 / \bar{Y}) \partial \Pi(q, \underline{\alpha}) / \partial q<\partial \Pi(q, \bar{\alpha}) / \partial q$. The factors listed in Proposition 4 favoring an optimistic growth strategy, namely, a high $\Pi_{\mathrm{S}}^{\mathrm{D}}(\bar{\alpha})$ and/or $\Pi(\underline{q}, \underline{\alpha})$ and a low $\Pi(\underline{q}, \bar{\alpha})$, are all reducing the risks associated with higher growth and yield a larger value of $Y$ : A larger duopoly profit or a lower monopoly profit for $S$ with a high-ability $J$ reduces $S$ 's opportunity cost of losing the high-ability $\mathrm{J}$; a larger monopoly profit for $\mathrm{S}$ when $\mathrm{J}$ has low ability reduces the expected cost of growing beyond $\underline{q}$.

The pessimistic growth equilibrium $\left(q^{*}<q\right)$ occurs under the opposite conditions, if the prospect of losing a high-ability J dominates the firm's objective. Though J's learning strategy is still mixed as described in Lemma 2 (so that he acquires ability $\bar{\alpha}$ with positive probability), growth is even below $\underline{q}$ because the sunk cost that a potential defection will generate is deemed quite large. Using the conditions given in Proposition 4, a low duopoly profit $\Pi_{\mathrm{S}}^{\mathrm{D}}(\bar{\alpha})$ for $\mathrm{S}$ implies a large opportunity cost of losing $\mathbf{J}$ and hence generates a prudent growth strategy. Similarly, S incurs a large loss from J's defection when a high ability makes a large difference to S's monopoly profit $(\Pi(\underline{q}, \bar{\alpha})$ increases or $\Pi(\underline{q}, \underline{\alpha})$ decreases $)$. On the other hand, since $x^{*}(q)$ is decreasing in $q$, firms adopting a low growth strategy are more likely to experience managerial defections, which in turn justifies their prudent growth strategy.

\section{Contractible promotion criteria}

Our model has no equilibria in which the firm has perfect information about the junior managers' ability at the defection/promotion stage. This feature of the model is entirely due to our "incomplete-contracts" approach, explicit in the assumption that the firm and the junior manager cannot sign a complete contract of contingencies to govern the late stages of their relationship. ${ }^{12}$ The lack of information generates two types of errors; an underestimated ability causes defection, while an overestimated ability retains an unqualified manager. We have, until here, assumed that the performance signal $g$ is not contractible. In Section 4 we derived an endogenous promotion criterion through the equilibrium path where S's optimal offer is $\bar{b}$ in the interval $\left[g_{\mathrm{C}}^{*}, \bar{g}\right]$ and $\underline{b}$ otherwise. Below we show that the strategic impact of firm growth on the junior managers' learning decision can be eliminated if performance signals are contractible.

\footnotetext{
${ }^{12}$ See Demougin and Siow (1994), (1996) for a discussion of the incomplete contracts approach and references to the literature using this assumption.
} 
Proposition 5. Assume that $g$ is contractible. Then, $S$ can induce a high ability on $J$ with probability one through a two-part signal-wage schedule $b(g)$ for the defection stage. The optimal schedule partitions the range of signals into two intervals $[g, \tilde{g})$ and $[\tilde{g}, \bar{g}]$, so that $\bar{b}$ is paid if $g \in[g, \tilde{g})$ and $\tilde{b}>\bar{b}$ is paid otherwise. The corresponding growth level is $\bar{q}$ and the probability of defection is zero.

Proof. To induce the learning strategy $x=1$ with zero defection probability, the signal-wage schedule must obviously satisfy $b \geqslant \bar{b}$ for all $g$. Consider the following two-part signal-wage schedule for the defection stage: $\mathrm{S}$ offers $\tilde{b}$ if $g \geqslant \tilde{g}_{\mathrm{C}}$ and $\bar{b}$ otherwise, where $\tilde{b}$ and $\tilde{g}_{\mathrm{C}}$ will be determined optimally through S's objective. Given this schedule, J's incentive compatibility constraint is $\bar{b} F_{\bar{\alpha}}\left(\tilde{g}_{\mathrm{C}}\right)+$ $\tilde{b}\left(1-F_{\bar{\alpha}}\left(\tilde{g}_{\mathrm{C}}\right)\right)-d(\bar{a}) \geqslant \bar{b} F_{\underline{\alpha}}\left(\tilde{g}_{\mathrm{C}}\right)+\tilde{b}\left(1-F_{\underline{\alpha}}\left(\tilde{g}_{\mathrm{C}}\right)\right)-d(\underline{\alpha})$ or

$$
(\tilde{b}-\bar{b})\left(F_{\underline{\alpha}}\left(\tilde{g}_{\mathrm{C}}\right)-F_{\bar{a}}\left(\tilde{g}_{\mathrm{C}}\right)\right) \geqslant d(\bar{\alpha})-d(\underline{\alpha}) .
$$

S's problem is thus to choose $q, \tilde{b}$ and $\tilde{g}_{\mathrm{C}}$ to maximize

$$
\Pi^{0}=-k(q)+\Pi(q, \bar{\alpha})-F_{\bar{\alpha}}\left(\tilde{g}_{\mathrm{C}}\right) \bar{b}-\left(1-F_{\bar{\alpha}}\left(\tilde{g}_{\mathrm{C}}\right)\right) \tilde{b}
$$

subject to (9). Note that the optimal growth is now $\bar{q}$ provided that the incentive compatibility constraint (9) holds. $\Pi^{0}$ is decreasing in $\tilde{b}$ and increasing in $\tilde{g}_{\mathrm{C}}$. Note also that the solution should bind the constraint (9), for otherwise $S$ would decrease $\tilde{b}$, hence the expected wage bill. Differentiating (9) we obtain

$$
\left[F_{\underline{\alpha}}\left(\tilde{g}_{\mathrm{C}}\right)-F_{\bar{a}}\left(\tilde{g}_{\mathrm{C}}\right)\right] \mathrm{d} \tilde{b}+(\tilde{b}-\bar{b})\left(f_{\underline{\alpha}}\left(\tilde{g}_{\mathrm{C}}\right)-f_{\bar{\alpha}}\left(\tilde{g}_{\mathrm{C}}\right)\right) \mathrm{d} \tilde{g}_{\mathrm{C}}=0 .
$$

Differentiating $\Pi^{0}$ with respect to $\tilde{b}$ and $\tilde{g}_{\mathrm{C}}$ and using (10), we see that the optimal $\tilde{g}_{\mathrm{C}}$ must satisfy ${ }^{13}$

$$
\frac{f_{\bar{\alpha}}\left(\tilde{g}_{\mathrm{C}}\right)}{1-F_{\bar{\alpha}}\left(\tilde{g}_{\mathrm{C}}\right)}=\frac{f_{\underline{\alpha}}\left(\tilde{g}_{\mathrm{C}}\right)}{1-F_{\underline{\alpha}}\left(\tilde{g}_{\mathrm{C}}\right)},
$$

and $\tilde{b}$ will be determined through (9). Since J's wage is at least $\bar{b}$ for all $g$, the probability of a defection is zero. Q.E.D.

The expected wage bill under the optimal two-part schedule introduced in Proposition 5 is $F_{\bar{\alpha}}\left(\tilde{g}_{\mathrm{C}}\right) \bar{b}+\left(1-F_{\bar{\alpha}}\left(\tilde{g}_{\mathrm{C}}\right)\right) \tilde{b}$, or using (9),

$$
\bar{b}+\frac{\left(1-F_{\bar{\alpha}}\left(\tilde{g}_{\mathrm{C}}\right)\right)(d(\bar{\alpha})-d(\underline{\alpha}))}{F_{\underline{\alpha}}\left(\tilde{g}_{\mathrm{C}}\right)-F_{\bar{\alpha}}\left(\tilde{g}_{\mathrm{C}}\right)} .
$$

\footnotetext{
${ }^{13}$ The critical value $\tilde{g}_{\mathrm{C}}$ equalizes the "hazard rates" under the two distributions. See Fudenberg and Tirole (1991), p. 267, for an interpretation.
} 
Since the wage bill when ability is observable is $\bar{b}$, the second term above represents the incentive cost of inducing $x=1$ with zero probability of defection. ${ }^{14}$ The importance of the firm's commitment to the promotion criterion should thus be clear: If ex-post the firm can costlessly deviate from the criterion and if $\mathbf{J}$ anticipates this, the outcome collapses to the equilibrium described in Proposition 3 where defection occurs with probability $x^{*}\left(q^{*}\right) F_{\bar{\alpha}}\left(g_{\mathrm{C}}^{*}\right)$.

\section{Concluding remarks}

The relationship between the parent firm and its junior manager is a joint venture with inherently uncertain future returns. Uncertainty stems from the parent's lack of information about junior managers' abilities at the promotion stage. It may cause defection of a skilled manager or an unqualified promotion, both unwanted outcomes from the perspective of the parent. The parties' decisions at the early stages of their relationship, e.g., the parent's growth decision and junior managers' incentives to acquire industry-specific abilities, will also be affected by this inherent uncertainty. We have studied the interaction between growth and managerial learning in a two-stage game where managerial abilities enhance both the returns to growth and junior managers' option of defection to establish a rival. The parent does not observe learning activities but an imperfect indicator (e.g., performance) of ability at the interim contract renewal date when it presents an offer.

The results and the predictions that can be distilled from our analysis are as follows. Firms with an internal reputation to honor a set of well-defined promotion criteria are likely to experience few defections and pursue growth objectives in accordance with the expected internal supply of skilled managerial input. The intuition behind this result is simple: as shown in Section 5, an appropriate and credible promotion criterion can eliminate the inherent uncertainty mentioned above by inducing a high learning effort with zero defection probability. In Section 2, Section 3 and Section 4 we focused on the alternative and more realistic case where the firm is not able to present such a credible promotion criterion. Then, expected opportunistic behavior in promotion decisions feeds back to generate noncooperative behavior in the early stages of firm-junior manager relationships: the firm holds up growth, the junior manager holds up learning. The model generates an endogenous equilibrium promotion criterion for this case. We have

\footnotetext{
${ }^{14}$ The commitment case is analogous to the standard principal-agent model with moral hazard. It is well known that under mild conditions the principal can induce the agent to take the first-best action (here, acquiring the high ability) through an output-contingent (here, signal-contingent) payment scheme. The major source of inefficiency in the standard principal-agent model under moral hazard is the agent's risk aversion, which generates a conflict between incentive provision and efficient risk sharing. Since $\mathrm{J}$ is risk-neutral here, the efficiency result in Proposition 5 follows.
} 
shown that equilibrium promotion criteria are tight in firms where junior managers face a high learning cost or a low outside return on their industry-specific learning (investment). When the junior manager has powerful learning incentives, the firm accordingly relaxes its promotion decision by offering the high wage in a wider range of performance signals. We also find that high-growth firms should experience few managerial defections but face a high probability of ex-post unqualified promotions. In other words, high growth softens the firm's promotion decisions, which in turn tends to offset the benefits expected from growth. When (as we assumed throughout the paper) junior managers' ability acquisition process is not directly observable, in the absence of a credible promotion criterion firm growth may turn out to be suboptimal or excessive with respect to the ex-post stock of managerial abilities.

We did not presume to explain fully all potential dimensions of firm-junior manager relationships, which are determined by considerations not captured by our model. One aspect of internal managerial markets is competition between junior managers for senior positions, or tournaments. The tournament version of our model with $\mathrm{n}$ junior managers is an interesting extension. If individual efforts to acquire managerial ability have no direct impact on other junior managers' distribution of performance signals, a symmetric equilibrium where managers randomize generates the promotion criterion $\left[g_{\mathrm{C}}^{*}, \bar{g}\right]$ for each manager, as in the present case of one junior manager. If we further assume concavity of the profit function with respect to the stock of managerial ability, it follows that firm growth per-manager is diminishing whereas the growth level is nondecreasing in the number of junior managers. The most interesting question that remains to be explored in the tournament version is the equilibrium relationship between the number of junior managers (the span of the firm) and individual learning incentives. Standard tournament (or, rat race) models predict a positive relation between these two variables under exogenous individual outside options. In the tournament version of our model the expected value of individual outside and inside options will depend on both the number of potential defections and the firm's growth strategy. This extension which we intend to explore in future research will also generate an endogenous span of the firm. ${ }^{15}$

Part of the sunk growth expenditure, denoted $q$ in the analysis, can be thought of as an investment on human capital and training, if the simple ability acquisition technology is modified to accommodate this possibility. In the absence of external effects, training expenditures and managers' effort to acquire a high ability would be strategic substitutes, and this would only strengthen the negative relationship we obtained between growth and learning incentives. However, training expenditures may also have a direct positive external effect on junior managers' learning

\footnotetext{
${ }^{15}$ See Demougin and Siow (1996) for an alternative approach to this issue.
} 
incentives, in particular, on their differential cost of learning $d(\bar{\alpha})-d(\underline{\alpha}){ }^{16}$ Training expenditures can reduce the cost of acquiring industry-specific knowledge, thus, reduce both $d(\underline{\alpha})$ and $d(\bar{\alpha})$. As a result, $d(\bar{\alpha})-d(\underline{\alpha})$ may either decrease or increase, that is, acquiring a high ability may become relatively more or less attractive for junior managers. By Proposition 2, a smaller (larger) $d(\bar{\alpha})-d(\underline{\alpha})$ will soften (tighten) the promotion criterion. Thus, in the relatively likely case where $d(\bar{\alpha})-d(\underline{\alpha})$ is decreasing in the firm's training expenditures, more training expenditures (as other types of growth expenditures) will soften the promotion criterion: by reducing the relative cost of acquiring a high ability, the firm is credibly signalling an increase in the probability of promotion. Our qualitative results may be affected only otherwise, if $d(\bar{\alpha})-d(\underline{\alpha})$ is increasing in training expenditures. In this unlikely case, more training may tighten the promotion criterion. $^{17}$

Another assumption implicit in our model is that the defecting manager's duopoly profit $\Pi_{\mathrm{J}}^{\mathrm{D}}(\alpha)$ does not depend on the parent firm's growth strategy. Firm growth may decrease $\Pi_{\mathrm{J}}^{\mathrm{D}}(\alpha)$ and even make it negative, reducing the defection probability to zero. ${ }^{18}$ Our analysis has ignored the fact that firms have several instruments to reduce defections. For instance, as Mortenson (1978) argues, managers' "switching costs" can be increased through accrued nonvested retirement and other benefits. In our model, the impact of such switching costs can be captured by a decrease in $\bar{b}$. The switching cost will alleviate the problem of successful defections but it will also have a negative impact on managerial learning due to standard moral hazard considerations. The firm will accordingly tighten its promotion decisions, as predicted by Proposition $2 .{ }^{19}$

We close the paper with a brief discussion of extending our model to the context of an oligopolistic market structure where firms compete for future market shares through their growth strategies. This extension promises valuable insights about the relationship between firm growth, evolution of market structure, promotion practices, managerial learning and career mobilities. In an oligopolistic context, individual firms' growth strategies will be interdependent because growth increases the demand for skilled managers at the defection/promotion stage. Highgrowth firms, as predicted by our model, will be soft in their promotion decisions

\footnotetext{
${ }^{16}$ We are grateful to a referee for bringing this issue to our attention.

${ }^{17}$ Note that a large increase in $d(\bar{\alpha})-d(\underline{\alpha})$ may even violate (A4), leaving us with the bad equilibrium in which the junior manager does not invest on learning with probability one. Then, of course, the firm would not invest on training and never promote the junior manager.

${ }^{18}$ The parent firm's problem, then, would partially be an entry deterrence problem where potential firms are established by defecting high-ability managers. The commitment value of firm growth as an entry deterrence device has been extensively studied in the entry deterrence literature. See for example Spence (1979) and Dixit (1980).

${ }^{19}$ See Bac (1997) for a discussion of switching costs in relationships governed by incomplete contracts.
} 
and potentially "aggressive" buyers of skilled managers. On the other hand, growth, hence the future demand for skilled managers, will depend on junior managers' individual learning incentives in their parent firms.

\section{Acknowledgements}

We are grateful to Bernard Beaudreau for helpful discussions on an earlier draft of the paper, and to two anonymous referees and an associate editor for their useful comments. Ismail Saglam acknowledges a grant in scope of the NATO Science Fellowship Programme awarded by the Scientific and Technical Research Council of Turkey (TUBITAK) and the support of the Center for Economic Design, Istanbul.

\section{Appendix A}

Proof of Lemma 1. (i) Recall that from (4) we have $\mu(\bar{\alpha} \mid g) \leqslant x$ for all $g \in[g, \bar{g}]$. From (5) we see that when $x<M(q)$ here exists no $g$ such that $\mu(\bar{\alpha} \mid g) \geqslant M(q)$. If $x=M(q)$, we have $g_{\mathrm{C}}(M(q), q)=\bar{g}$ because $\mu(\bar{\alpha} \mid g)=M(q)$, and $\mu(\bar{\alpha} \mid g)$ is increasing in $g$ for $x \in(0,1)$ and $g \neq g$. On the other hand if $x=1$, applying L'Hopital's rule to the limit of $\mu(\bar{a} \mid g)$ as $g \rightarrow g$, we find that $g_{\mathrm{C}}(x, q)=g$. That is, $\mathrm{S}$ will offer $\bar{b}$ no matter $g$ and $q$, if $\mathrm{J}$ acquires ability $\bar{\alpha}$ for sure. This offer strategy of $\mathrm{S}$ is not confined to $x=1$, however. There is a lower bound $Z(q)$ of $x$ such that $g_{\mathrm{C}}(x, q)=\underline{g}$ for $x \in[Z(q), 1]$ :

$$
Z(q)=\inf \left\{x \mid \lim _{g \rightarrow \underline{g}}\left(1+\frac{(1-x)}{x} \frac{f_{\underline{\alpha}}(g)}{f_{\bar{\alpha}}(g)}\right)^{-1} \geqslant M(q)\right\},
$$

where L'Hopital's rule is applied to the limit of $\mu(\bar{\alpha} \mid \mathrm{g})$ as $g \rightarrow \underline{g}$. Thus, if $x \in(M(q), Z(q))$, then $g_{\mathrm{C}}(x, q) \in(g, \bar{g})$.

(ii) ${ }^{20}$ Equating the right hand sides of (4) and (5), and rearranging, we get

$$
\frac{F_{\underline{\alpha}}\left(g_{\mathrm{C}}\right)}{F_{\bar{\alpha}}\left(g_{\mathrm{C}}\right)}=\frac{(1 / M(q))-1}{(1 / x)-1} \text {. }
$$

Since $M^{\prime}(q)<0$ for all $q \in[0, \bar{q})$, the right hand side of the above equation is increasing in both $q$ and $x$. The left hand side is decreasing in $g_{\mathrm{C}}$ by Assumption (A1); therefore $g_{\mathrm{C}}$ must be nonincreasing in $x$ and $q$ in the interval $(\underline{g}, \bar{g}]$. Q.E.D.

\footnotetext{
${ }^{20}$ We are grateful to associate editor Simon Anderson for an argument that considerably simplified this part of the proof.
} 
Proof of Lemma 2. The first step is to show that $x=0$ or $x=1$ cannot be equilibrium strategies. $x>0$ is already implied by $g_{\mathrm{C}}(0, q)=\bar{g}$ and (A4). Now assume $x^{*}(q)=1$ for some $q$, which means that $\mathrm{J}$ acquires ability $\bar{\alpha}$ with probability one. S then offers $\bar{b}$ at the defection stage no matter what $g$ is and $\mathbf{J}$ obtains the payoff $\bar{b}-d(\bar{\alpha})$. But decreasing $x$ by $\mathrm{d} x<1-Z(q)$ increases this payoff by $[d(\bar{\alpha})-d(\underline{\alpha})] \mathrm{d} x$ because $\mathrm{S}$ will still offer $\bar{b}$ for all realizations of $g$. Therefore $x=1$ cannot be an equilibrium strategy, which implies that $\underline{x} \in(0,1)$ and $\bar{x} \in(0,1)$.

We show below that $x^{*}(q)$ is decreasing in $q$ for all $q$ such that $x^{*}(q) \in(0,1)$. For such values of $x$, recall that $g_{\mathrm{C}}=g_{\mathrm{C}}\left(x^{*}(q), q\right)$ and (5) holds with equality. Rearranging terms in (5), we can write

$$
x^{*}(q)=\left[1+\left(\frac{1}{M(q)}-1\right) \frac{F_{\bar{\alpha}}\left(g_{C}\right)}{F_{\underline{\alpha}}\left(g_{\mathrm{C}}\right)}\right]^{-1},
$$

which is clearly decreasing in $q$ for all $q \in[0, \bar{q}]$. It follows that $x^{*}(\bar{q})=\underline{x}<\bar{x}=$ $x *(0)$. Q.E.D.

Proof of Proposition 3. We have previously shown that $x^{*}(q) \in(0,1)$. We claim that $\partial \Pi^{0} / \partial q<0$ for all $q \geqslant \bar{q}$. Let us introduce the shorthand notation $F_{\alpha}\left(g_{\mathrm{C}}^{*}\right)=$ $F_{\alpha}$. We consider first $\partial \Pi^{0} /\left.\partial q\right|_{q=\bar{q}}$ which, using the optimality condition $k^{\prime}(\bar{q})=$ $\partial \Pi(\bar{q}, \bar{\alpha}) / \partial q$, can be written as

$$
\begin{aligned}
\left.\frac{\partial \Pi^{0}}{\partial q}\right|_{q=\bar{q}}= & -\frac{\partial \Pi(\bar{q}, \bar{\alpha})}{\partial q}+x^{*}(\bar{q})\left(1-F_{\bar{\alpha}}\right) \frac{\partial \Pi(\bar{q}, \bar{\alpha})}{\partial q} \\
& +\left(1-x^{*}(\bar{q})\right) \frac{\partial \Pi(\bar{q}, \underline{\alpha})}{\partial q}+\frac{\partial x^{*}(\bar{q})}{\partial q}\left\{\left(1-F_{\bar{a}}\right)(\Pi(\bar{q}, \bar{\alpha})-\bar{b})\right. \\
& \left.+F_{\bar{\alpha}} \Pi_{\mathrm{S}}^{\mathrm{D}}(\bar{\alpha})-\Pi(\bar{q}, \underline{\alpha})+\bar{b}-(\bar{b}-\underline{b}) F_{\underline{\alpha}}\right\} .
\end{aligned}
$$

Using the definition of $M(q)$ given in (5), we can solve for $x^{*}(\bar{q})$ from (11). We then obtain

$$
\begin{aligned}
\frac{\partial x^{*}(\bar{q})}{\partial q} & =-\left[x^{*}(\bar{q})\right]^{2} \frac{F_{\bar{\alpha}}}{F_{\underline{\alpha}}} \frac{M^{\prime}(\bar{q})}{[M(\bar{q})]^{2}} \\
& =-\frac{x^{*}(\bar{q}) F_{\bar{\alpha}} \partial \Pi(\bar{q}, \bar{\alpha}) / \partial q}{F_{\underline{\alpha}}(\bar{b}-\underline{b})+F_{\bar{\alpha}}\left[\Pi(\bar{q}, \bar{\alpha})-\Pi_{\mathrm{S}}^{\mathrm{D}}(\bar{\alpha})-(\bar{b}-\underline{b})\right]},
\end{aligned}
$$

where the last equality is obtained by substituting the derivative of $M(q)$. The first three terms in (12) can be arranged to yield

$$
-\left(1-x^{*}(\bar{q})\right)\left(\frac{\partial \Pi(\bar{q}, \bar{\alpha})}{\partial q}-\frac{\partial \Pi(\bar{q}, \underline{a})}{\partial q}\right)-x^{*}(\bar{q}) F_{\bar{a}} \frac{\partial \Pi(\bar{q}, \bar{\alpha})}{\partial q} .
$$


As for the last term in (12), it can be written as

$$
\begin{aligned}
& -\frac{x^{*}(\bar{q}) F_{\bar{\alpha}} \partial \Pi(\bar{q}, \bar{\alpha}) / \partial q}{F_{\underline{\alpha}}(\bar{b}-\underline{b})+F_{\bar{\alpha}}\left[\Pi(\bar{q}, \bar{\alpha})-\Pi_{\mathrm{S}}^{\mathrm{D}}(\bar{\alpha})-(\bar{b}-\underline{b})\right]} \times\{\Pi(\bar{q}, \bar{\alpha})-\Pi(\bar{q}, \underline{\alpha}) \\
& \left.+F_{\bar{\alpha}} \underline{b}-\left(F_{\underline{\alpha}}(\bar{b}-\underline{b})+F_{\bar{\alpha}}\left[\Pi(\bar{q}, \bar{\alpha})-\Pi_{\mathrm{S}}^{\mathrm{D}}(\bar{a})-(\bar{b}-\underline{b})\right]\right)\right\},
\end{aligned}
$$

where we add and subtract $F_{\bar{\alpha}} \underline{b}$, and use the expressions for $\partial x^{*}(q) / \partial q$ and $x^{*}(q)$ obtained above. Rearranging terms, the last term in (12) becomes

$$
-x^{*}(\bar{q}) F_{\bar{\alpha}} \frac{\partial \Pi(\bar{q}, \bar{\alpha})}{\partial q}\left\{\frac{\Pi(\bar{q}, \bar{\alpha})-\Pi(\bar{q}, \underline{\alpha})+F_{\bar{\alpha}} \underline{b}}{F_{\underline{\alpha}}(\bar{b}-\underline{b})+F_{\bar{\alpha}}\left[\Pi(\bar{q}, \bar{\alpha})-\Pi_{\mathrm{S}}^{\mathrm{D}}(\bar{\alpha})-(\bar{b}-\underline{b})\right]}-1\right\} .
$$

Combining these terms, we can write (12) as

$$
-\left(\frac{\partial \Pi(\bar{q}, \bar{\alpha})}{\partial q}-\frac{\partial \Pi(\bar{q}, \underline{\alpha})}{\partial q}\right)\left(1-x^{*}(\bar{q})\right)-x^{*}(\bar{q}) F_{\bar{\alpha}} \frac{\partial \Pi(\bar{q}, \bar{\alpha})}{\partial q} B(\bar{q})<0,
$$

where

$$
B(\bar{q})=\frac{\Pi(\bar{q}, \bar{\alpha})-\Pi(\bar{q}, \underline{\alpha})+F_{\bar{\alpha}} \underline{b}}{F_{\underline{\alpha}}(\bar{b}-\underline{b})+F_{\bar{\alpha}}\left[\Pi(\bar{q}, \bar{\alpha})-\Pi_{\mathrm{S}}^{\mathrm{D}}(\bar{\alpha})-(\bar{b}-\underline{b})\right]}>0 ;
$$

hence the expected marginal profit of growth is negative at $q=\bar{q}$. To show that $\partial \Pi^{0} / \partial q<0$ for all $q>\bar{q}$, note that $k^{\prime}(q)>\partial \Pi(q, \bar{\alpha}) / \partial q$, hence we can write $k^{\prime}(q)=\partial \Pi(q, \bar{\alpha}) / \partial q+\epsilon(q)$ where $\epsilon(q)$ is increasing in $q$. Using this fact in (12), the first term becomes $-\partial \Pi(q, \bar{\alpha}) / \partial q-\epsilon(q)$; replacing $\bar{q}$ in (12) by $q$ and following the steps in the proof above yields the result:

$$
\begin{aligned}
& -\epsilon(q)-\left(\frac{\partial \Pi(q, \bar{\alpha})}{\partial q}-\frac{\partial \Pi(q, \underline{\alpha})}{\partial q}\right)\left(1-x^{*}(q)\right)-x^{*}(q) F_{\bar{\alpha}} \frac{\partial \Pi(q, \bar{\alpha})}{\partial q} B(q) \\
& <0 .
\end{aligned}
$$

Note that the sum of the first two terms above is negative because $\partial \Pi(q, \bar{\alpha}) / \partial q=$ $k^{\prime}(q)-\epsilon(q)$ and $k^{\prime}(q)>\partial \Pi(q, \underline{\alpha}) / \partial q$. Q.E.D.

Proof of Proposition 4. Using the procedure in the proof of Proposition 3 and the fact that $\partial \Pi(\underline{q}, \underline{\alpha}) / \partial q=k^{\prime}(\underline{q})$, we can write

$$
\begin{aligned}
\left.\frac{\partial \Pi^{0}}{\partial q}\right|_{q=\underline{q}}= & -\frac{\partial \Pi(\underline{q}, \underline{\alpha})}{\partial q}+x^{*}(\underline{q})\left(1-F_{\bar{\alpha}}\right) \frac{\partial \Pi(\underline{q}, \bar{\alpha})}{\partial q}+\left(1-x^{*}(\underline{q})\right) \frac{\partial \Pi(\underline{q}, \underline{\alpha})}{\partial q} \\
& +\frac{\partial x^{*}(\underline{q})}{\partial q}\left\{\left(1-F_{\bar{\alpha}}\right)(\Pi(\underline{q}, \bar{\alpha})-\bar{b})+F_{\bar{\alpha}} \Pi_{\mathrm{S}}^{\mathrm{D}}(\bar{\alpha})-\Pi(\underline{q}, \underline{\alpha})+\bar{b}\right. \\
& \left.-(\bar{b}-\underline{b}) F_{\underline{\alpha}}\right\} .
\end{aligned}
$$


Substituting for $\partial x^{*}(q) / \partial q$ and rearranging terms, we get

$$
\left.\frac{\partial \Pi^{0}}{\partial q}\right|_{q=\underline{q}}>0 \text { if } \frac{\partial \Pi(\underline{q}, \bar{\alpha})}{\partial q}-\frac{\partial \Pi(\underline{q}, \underline{\alpha})}{\partial q}>F_{\bar{\alpha}} \frac{\partial \Pi(\underline{q}, \bar{\alpha})}{\partial q} B(\underline{q}),
$$

where $B(q)$ is given in (13). Therefore the condition can be expressed as

$$
\frac{\partial \Pi(\underline{q}, \underline{\alpha})}{\partial q}<\left[1-F_{\bar{\alpha}} B(\underline{q})\right] \frac{\partial \Pi(\underline{q}, \bar{\alpha})}{\partial q}=Y \frac{\partial \Pi(\underline{q}, \bar{\alpha})}{\partial q} .
$$

The expression of $Y$ is given in the text; it can be derived by using the expression of $B(q)$ above. It is straightforward to verify that the condition above is more likely to hold when $\Pi_{\mathrm{S}}^{\mathrm{D}}(\bar{\alpha})$ and $\Pi(\underline{q}, \underline{\alpha})$ are higher, or $\Pi(\underline{q}, \bar{\alpha})$ is lower. Q.E.D.

\section{References}

Bac, M., 1997. Bilateral relationships governed by incomplete contracts. Journal of Institutional and Theoretical Economics 153, 320-333.

Baumol, W.J., 1959. Business Behavior, Value, and Growth. Harcourt, Brace and Jovanovich, New York.

Carmichael, H.L., 1983. Firm-specific human capital and promotion ladders. Bell Journal of Economics 14, 251-258.

Demougin, D., Siow, A., 1994. Careers in ongoing hierarchies. American Economic Review 84, 1261-1277.

Demougin, D., Siow, A., 1996. Managerial husbandry and the dynamics of ongoing hierarchies. European Economic Review 40, 1483-1499.

Demsetz, H., 1973. Industry structure, market rivalry and public policy. Journal of Law and Economics 16, 1-9.

Dixit, A., 1980. The role of investment in entry deterrence. Economic Journal 90, 95-106.

Fudenberg, D., Tirole, J., 1991. Game Theory. MIT Press, Cambridge.

Gilson, R.J., Mnookin, R.H., 1989. Coming of age in a corporate law firm: The economics of associate career patterns. Stanford Law Review 41, 567-595.

Kihlstrom, R., Laffont, J.J., 1979. A General equilibrium entrepreneurial theory of the firm based on risk aversion. Journal of Political Economy 87, 719-748.

Kotter, J.P., 1982. The General Managers. The Free Press, New York.

Lucas, R., 1978. On the size distribution of business firms. Bell Journal of Economics 9, 508-523.

MacDonald, G.M., 1982. Information in production. Econometrica 50, 1143-1162.

Maister, D.H., 1993. Managing the Professional Service Firm. The Free Press, New York.

Malos, S.B., Campion, M.A., 1995. An options-based model of career mobility in professional service firms. Academy of Management Review 20, 611-644.

Marris, R., 1963. A model of managerial enterprise. Quarterly Journal of Economics 77, 185-209.

Marshall, A., 1890. Principles of Economics. Macmillan, London.

Mortenson, D.T., 1978. Specific capital and labor turnover. Bell Journal of Economics 13, 206-213.

Nelson, R.L., 1988. Partners with Power: The Social Transformation of the Large Law Firm. University of California Press, Berkeley.

Penrose, E., 1959. The Theory of the Growth of the Firm. Basic Blackwell, Oxford.

Prescott, E., Visscher, M., 1980. Organization capital. Journal of Political Economy 88, 446-461.

Ricarti-i-Costa, J.E., 1988. Managerial task assignments and promotions. Econometrica 56, 449-466. 
Siow, A., 1994. Hierarchical careers. Industrial Relations 33, 83-105.

Shetty, Y.K., Peery, N.S., 1976. Are top executives transferable across companies? Business Horizons $19,23-28$.

Spence, M., 1979. Investment strategy and growth in a new market. Bell Journal of Economics 10, $1-10$.

Tuckel, P., Siegel, K., 1983. The myth of the migrant manager. Business Horizons 26, 64-70.

Williamson, O., 1985. The Economic Institutions of Capitalism. The Free Press, New York. 